\title{
Identification of Bunyamwera and Possible Other Orthobunyavirus Infections and Disease in Cattle during a Rift Valley Fever Outbreak in Rwanda in 2018
}

\author{
Marie Fausta Dutuze, ${ }^{1,2}$ Angelique Ingabire ${ }^{3}$ Isidore Gafarasi, ${ }^{3}$ Solange Uwituze ${ }^{3}$ Manassé Nzayirambaho, ${ }^{4}$ and \\ Rebecca C. Christofferson ${ }^{1 *}$ \\ ${ }^{1}$ School of Veterinary Medicine, Louisiana State University, Baton Rouge, Louisiana; ${ }^{2}$ College of Agriculture and Animal Sciences and Veterinary \\ Medicine, University of Rwanda, Kigali, Rwanda; ${ }^{3}$ Rwanda Agriculture Board, Kigali, Rwanda; ${ }^{4}$ School of Public Health, University of Rwanda, \\ Kigali, Rwanda
}

\begin{abstract}
In 2018, a large outbreak of Rift Valley fever (RVF)-like illness in cattle in Rwanda and surrounding countries was reported. From this outbreak, sera samples from 157 cows and 28 goats suspected to be cases of RVF were tested to confirm or determine the etiology of the disease. Specifically, the hypothesis that orthobunyaviruses-Bunyamwera virus (BUNV), Batai virus (BATV), and Ngari virus (NRIV)—were co-circulating and contributed to RVF-like disease was tested. Using reverse transcriptase-polymerase chain reaction (RT-PCR), RVFV RNA was detected in approximately $30 \%$ of acutely ill animals, but in all cases of hemorrhagic disease. Seven cows with experienced abortion had positive amplification and visualization by gel electrophoresis of all three segments of either BUNV or BATV, and three of these were suggested to be coinfected with BUNV and BATV. On sequencing, five of these seven cows were conclusively positive for BUNV. However, in several other animals, sequencing was successful for some but not all segments of targeted viruses BUNV and BATV. In addition, there was evidence of RVFV-orthobunyavirus coinfection, through RT-PCR/gel electrophoresis and subsequent Sanger sequencing. In no cases were we able to definitely identify the specific coinfecting viral species. This is the first time evidence for orthobunyavirus circulation has been molecularly confirmed in Rwanda. Furthermore, RT-PCR results suggest that BUNV and BATV may coinfect cattle and that RVFV-infected animals may be coinfected with other orthobunyaviruses. Finally, we confirm that BUNV and, perhaps, other orthobunyaviruses were cocirculating with RVFV and contributed to the burden of disease attributed to RVFV in Rwanda.
\end{abstract}

\section{INTRODUCTION}

The group of viruses commonly referred to as bunyaviruses have caused diseases of zoonotic and economic importance globally since the beginning of the twentieth century. ${ }^{1-4}$ In Africa, Rift Valley fever virus (RVFV) was first identified and characterized in 1912 and further detected as the etiological agent of an epizootic outbreak in Kenya in $1930 .^{5-7}$ Rift Valley fever virus is a vector-borne virus that causes disease in humans, livestock, and wildlife ruminant species. ${ }^{1,6,8,9}$ In animals, it is clinically characterized by abortions and stillbirths, hepatitis, and hemorrhagic fever in severe cases. ${ }^{8,10,11}$ In humans, the mild form is characterized by a self-limiting febrile illness, but individuals may progress to severe disease manifesting as hemorrhagic fever, encephalitis, vision loss, and conjunctivitis. ${ }^{8,12-18}$ These clinical manifestations are common in many diseases caused by bunyaviruses. ${ }^{2,19,20}$

Although RVFV has a broad range of identified vectors consisting of mosquitoes, ticks, and flies, the primary vectors are Aedes spp. and Culex spp. mosquitoes. ${ }^{21-28} \mathrm{Rift}$ Valley fever virus consistently circulates in domestic ruminants and human populations throughout different countries of Africa and the Arabian Peninsula where it causes significant outbreaks associated with livestock mortality, associated economic losses, and human mortalities. ${ }^{1,7,29-34}$ The virus is maintained during interepidemic periods by transovarial transmission in Aedes mosquitoes, and the resurgence of outbreaks is facilitated by periodic rainfall and flooding due to the intertropical convergence of air currents from southern and northern hemispheres which leads to a seasonal emergence of infected Aedes mosquitoes. ${ }^{27,35}$

*Address correspondence to Rebecca Christofferson, School of Veterinary Medicine, Skip Bertman Dr., Baton Rouge, LA 70803. E-mail: rcarri1@|su.edu
After the emergence of infected Aedes mosquitoes, an outbreak may be sparked, but the epidemic is likely maintained by Culex spp. ${ }^{35}$ In East Africa, this cycling pattern has been recognized since the 1970s with large outbreaks occurring in 1977 (Egypt), ${ }^{15}$ 1997-1998 (Kenya), ${ }^{33}$ 2006-2008 (Somalia, Tanzania, and Kenya), ${ }^{36,37}$ and 2018 (Kenya, Uganda, and Rwanda). ${ }^{37-39}$

In Rwanda, the only bunyavirus regularly surveilled is RVFV and is often clinically diagnosed. The first molecularly confirmed case of RVF was reported in Bugesera in 2011 after unusually high rates of abortions in domestic ruminants (mainly cattle) during the period of May-June were observed. ${ }^{40,41}$ Since then, RVF has become endemic with sporadic cases reported year round in the eastern part of the country and higher intensity outbreaks in May-June and December-January following the rainy seasons of MarchApril and October-November. ${ }^{40,41}$ For prevention, livestock are recommended to be regularly vaccinated with live attenuated Rift Valley fever vaccine prepared from Smithburn's attenuated strain of RVFV (RIFTVAX, Kenya Veterinary Vaccines Production Institute, Nairobi, Kenya). ${ }^{40}$ However, vaccine uptake and compliance rates are unknown.

Although RVFV is the most recognized and significant arbovirus in the region, many other zoonotic Bunyaviruses, such as Bunyamwera virus (BUNV), Batai virus (BATV), and Ngari virus (NRIV), circulate in East Africa (reviewed in ref. 3). Bunyamwera virus was first identified in Uganda (1943) and since has been regularly isolated in Tanzania, Kenya, and Uganda between 1945 and 2012.,42-44 Batai virus was first identified in Uganda (1966) and highly suspected in Sudan by serological assay (1988). ${ }^{45,46} \mathrm{Ngari}$ virus was first identified as an etiological agent of fatal hemorrhagic fever outbreak in Kenya (1997-1998). ${ }^{43,47,48}$ Despite their obvious potential to be of public and One Health importance, BUNV, BATV, and NRIV are not ordinarily included in diagnostic panels and could be cryptically circulating throughout sub-Saharan Africa. 
Bunyamwera virus, BATV, and NRIV belong to the taxonomic genus Orthobunyavirus, and NRIV is the natural reassortant of BUNV and BATV $\left(B U N V_{L} B A T V_{M} B U N V_{S}\right){ }^{48}$ Bunyamwera virus, BATV, and NRIV are transmitted by similar vectors as RVFV and infect similar vertebrate hosts, and infection with these viruses have been characterized with similar clinical manifestations. ${ }^{47,48}$ Specifically, the disease associated with BUNV has been reported to cause mild symptoms, such as fever, joint pain, and rash, in many mammals, including humans. ${ }^{42,49-51}$ Batai virus causes a mild flu-like illness in humans and is associated with a more severe disease in ruminants where it is manifested by abortions, premature births, and genetic defects. ${ }^{49,52,53}$ Ngari virus has been associated with fatal hemorrhagic fevers in both humans and ruminants. ${ }^{54,55}$ In 2018, the ICTV suggested a reorganization of Bunyavirus taxonomy, whereby the Rift Valley fever virus is now classified in the family Phenuiviridae and the orthobunyaviruses are now in the family Peribunyaviridae. However, this reorganization has not been uniformly adopted. ${ }^{56,57}$

In 2018, there were unusually heavy rainfalls that led to explosion of RVFV in East African countries (Rwanda, Kenya, Uganda, and Tanzania). This was the most intense occurrence of RVF in Rwanda as it caused many cases of death and/or abortion cases in the ruminant population and the deaths of two veterinarians. ${ }^{38,39}$ In addition, there was likely an underreporting of RVF cases of small ruminants because of their low economic and cultural importance in Rwanda. Diagnosis of cattle was primarily by clinical manifestations, not by molecular techniques.

The outbreak started in Ngoma and Kirehe districts (Eastern Province) of Rwanda at the end of May, and there were still many cases reported through the end of July in these two districts. The outbreak spread to other parts of the other districts of Eastern Province (Kayonza, Gatsibo, and Rwamagana). The Southern Province was also heavily affected followed by the Northern Province. The Western Province and Kigali city were affected late and at low levels. Animal movements were banned from mid-June to the end of July in an effort to slow the progress of the outbreak. Widespread human cases were not documented, excepting the deaths of two veterinary officers. The Rwanda Agriculture Board initiated a massive vaccination campaign of health and nonpregnant animals, and transmission was interrupted and the outbreak ended in July 2018.

Some samples from abortions were tested to confirm RVFV early in the outbreak, but diagnosis was mostly made based on clinical signs. Thus, we undertook to molecularly confirm RVFV as the etiological agent of RVF-like illness, and further tested samples to determine whether BUNV, BATV, or NRIV might be co-circulating and contributed to the burden of disease. $^{3}$

\section{MATERIALS AND METHODS}

Ethical considerations. This study was performed in conjunction with the Rwanda Agriculture Board and approved by the Institutional Review Board of the University of Rwanda in the College of Medicine and Health Sciences (Ref 026/17 DRIPGS/2017 of October 19, 2017) and by the Louisiana State University Institutional Animal Care and Use Committee (protocol \#17-085).
Sample collection and handling. One hundred fifty-seven blood samples were collected from cattle and 28 from goats suspected of RVFV infection in Rwanda between May 29 and July 25,2018 . The inclusion criteria for blood collection were at least one of the following: having aborted in less than a week, presenting with signs of hemorrhagic fever, history of death suspected for RVF in the same farm in less than 3 days, and history of abortion suspected to be associated with RVF in less than 3 days. Calves whose mothers presented with signs of hemorrhagic fever or had died of suspected RVF within 3 days were sampled as well. Blood was collected in 5-mL purple-top vacutainer tubes (without anticoagulant). Demographic information of farmers such as address and complete identification of sampled animals (age, gender, breed, clinical signs, status of RVFV vaccination, and breed) were also collected. From the field, samples were transported to the virology laboratory of Rwanda Agriculture Board immediately at Rubirizi station. The samples were then put into $2-\mathrm{mL}$ Eppendorf tubes and kept in $-80^{\circ} \mathrm{C}$, and subsequently, the samples were shipped to Louisiana State University where they were tested for RVFV and BUNV, BATV, and NRIV as described in the following paragraphs.

Viral RNA extraction and cDNA synthesis. Each sample was stored in DNA/RNA Shield (Zymo Research, \#R1100, Irvine, CA). Before extraction of RNA, TRI Reagent (SigmaAldrich, \#T9424, St. Louis, MO) was added and then viral RNA was extracted using Direct-zol ${ }^{\mathrm{TM}}$ MiniPrep kit (Zymo Research, \#R2052) according to the manufacturer's instructions. First-step total cDNA synthesis was performed on viral RNA using random hexamers and $1 \mu \mathrm{L}$ dNTPs and run on a thermocycler at $65^{\circ} \mathrm{C}$ for 5 minutes. Ten microliters of sample was then mixed with $2 \mu \mathrm{L} 10 \times \mathrm{RT}$ buffer, $4 \mu \mathrm{L} 25 \mathrm{mM} \mathrm{MgCl}_{2}, 2 \mu \mathrm{L}$ $0.1 \mathrm{~m}$ dithiothreitol (DTT), $1 \mu \mathrm{L}$ RNase OUT, and $1 \mu \mathrm{L}$ SuperScript III RT kit (Invitrogen, \#18080-051, Carlsbad, CA). The samples were then run on the thermocycler with the following cycling parameters: $25^{\circ} \mathrm{C}$ for 10 minutes, $50^{\circ} \mathrm{C}$ for 50 minutes, and $80^{\circ} \mathrm{C}$ for 5 minutes. One microliter $\mu \mathrm{L}$ of RNase $\mathrm{H}$ was added, and the samples were put back on the thermocycler at $37^{\circ} \mathrm{C}$ for 20 minutes. Totally, $21 \mu \mathrm{L}$ per sample was collected and kept in $-20^{\circ} \mathrm{C}$ until use.

Primer design for BUNV, BATV, and NRIV. The success of primers was confirmed using viral stocks: 6547-8, MM2222, and DAK-AR D28542 as the strain designations for BUNV, BATV, and NRIV, respectively, that were used throughout this study (Supplemental Figure S1). The prototype strain of BUNV isolated from Aedes spp. mosquitoes in Uganda in 1943 is 6547-8 (GenBank accession numbers: X14383, M11852, and

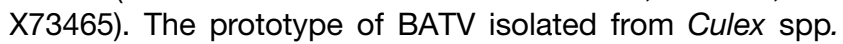
mosquitoes in Malaysia in 1955 is MM2222 (GenBank accession numbers: AB257766, JX8446595-97, and X73464). DAK-AR D28542 strain of NRIV was isolated from Aedes male mosquitoes in Senegal in 1985 (GenBank accession number: AY593728-29). The viruses were obtained from the World Reference Center for Emerging Viruses and Arboviruses at the University of Texas Medical Branch (UTMB).

PCR primers were designed using IDTDNA (https:// www.idtdna.com) PrimerQuest tool for all three gene segments for each virus (Supplemental Table S1): small (S), medium (M), and large (L) segments. The segments were tested for cross-reactivity (Supplemental Figure S1). As expected, the BUNV $S$ and $L$ primers cross-amplified the NRIV $S$ and $L$ segments, and the NRIV $L$ primers cross-amplified the BUNV L segment. However, the NRIV S primers only weakly 
cross-amplified the BUNV S segment, and there was no cross-amplification of the BUNV M segment by the NRIV M primers, nor was there cross-amplification of NRIV M segment by the BATV primers or vice versa (Supplemental Figure S1). Amplification of targets was performed on the thermocycler with the following cycling parameters: $95^{\circ} \mathrm{C}$ for 15 minutes; 35 cycles of $94^{\circ} \mathrm{C}$ for 30 seconds, $54^{\circ} \mathrm{C}$ for 30 seconds, $72^{\circ} \mathrm{C}$ for 1 minute, and $72^{\circ} \mathrm{C}$ for 10 minutes; and a $10^{\circ} \mathrm{C}$ hold until samples were removed and placed in $-20^{\circ} \mathrm{C}$ until further use. The primer sequences, size of amplicon, and accession number of gene segments are given in Supplemental Table S1.

Targeted cDNA amplification and sequencing. To test the aforementioned primers for sequencing abilities, we sequenced cDNA from stocks of BUNV, BATV, and NRIV from the WHO reference center (strains 6547-8, MM2222, and DAK-AR D28542, respectively). Sequencing was performed by Gene Probes and Expression Systems Laboratory of the Division of Biotechnology and Molecular Medicine at the Louisiana State University School of Veterinary Medicine. Sequencing was performed on a Beckman Coulter 8800 (Pasadena, CA) using the manufacturer's reagents and methods. ${ }^{58}$ All amplicons were successfully sequenced, and when blasted using NCBI Nucleotide BLAST (https://blast.ncbi.nlm.nih.gov/ Blast.cgi), all segments identified as belonging to their respective viruses (Supplemental Table S2).

Samples were first tested for RVFV infection by conventional PCR using primers targeting the conserved 90-nt region of the $L$ segment and using the same cycling parameters as in ref. ${ }^{59}$ Amplicons were stained by GelRed (Biotum, Cat No. 41003), run on $2 \%$ agarose gel with $1 \times$ TAE buffer at $100 \mathrm{~V}$ for 1 hour, and visualized with Bio View UV Light transilluminator. cDNA of RVFV-negative samples were pooled by 5-7 according to the districts of origin and were tested for BUNV, BATV, and NRIV. Samples belonging to positive pools were then tested individually. Rift Valley fever virus-positive samples were also tested for the three orthobunyaviruses. Detection of the three orthobunyaviruses was done by targeting all the three segments $S, M$, and $L$ for each virus by PCR.

Positive samples via RT-PCR were then sent to the Gene Probes and Expression Systems Laboratory of the Division of Biotechnology and Molecular Medicine at the Louisiana State University School of Veterinary Medicine for sequencing. Sequencing was performed on a Beckman Coulter 8800 (Pasadena, CA) using the manufacturer's reagents and methods. ${ }^{58}$ For all but one sample, sequences generated from the forward and reverse primers were aligned using NCBI Nucleotide BLAST (https://blast.ncbi.nlm.nih.gov/Blast.cgi), and the aligned FASTA files were then used to determine the identity of the sequences using BLASTnt (for one positive sample (Batai, 109S), double coverage was not achieved before sample volume was depleted and only the forward primer-derived sequence is available). All sequences were submitted to the GenBank using the Banklt submission tool. We classify RT-PCR positive, sequencing negative as "suggestive" and RT-PCR, sequencing positive samples as "positive."

\section{RESULTS}

Rift Valley fever diagnosis confirmation and sample demographics. There were more cows sampled than goats because of the economic and cultural importance of cows. Twelve goats were positive to RVFV, whereas 44 cattle were positive to RVFV via RT-PCR. More than $97 \%$ of samples were female, with the exception of four male calves included because their mothers had hemorrhagic fever symptoms and/or mothers had died within the last 3 days before sampling (full demographic details are given in Supplemental Table S3). Approximately, $79.5 \%$ of the 185 samples came from family farms compared with commercial farms. Cattle were identified as either exotic, local, or crossbreed. Of the 157 cows, $65.6 \%$ were classified as crossbreed, $25.5 \%$ as exotic breeds, and the remainder were classified as local breed. The study was not designed to test for differences in positivity among breeds. According to owners, none of the sampled animals were vaccinated for RVFV. In total, 30.3\% (56/185) samples were positive to RVFV-12 goats and 44 cattle. Of those that were positive for RVFV, $26.7 \%$ had signs of hemorrhagic disease, whereas $82.1 \%$ presented with abortion. All 12 goats that were RVFV positive experienced abortion and one had hemorrhagic fever, whereas $85.0 \%$ of cattle experienced abortion (34/40 female cattle) and 14 had hemorrhagic fever. All cases of hemorrhagic disease $(n=15)$ were positive for RVFV via RT-PCR and resulted in death 1-4 days after sample collection, and three of the four were the cases in cows and one case was in a goat.

Suggested circulation of orthobunyaviruses via RTPCR. Among the 129 RVF-negative samples, seven were positive to BUNV and/or BATV. Two samples were exclusively positive to BUNV, two were exclusively positive to BATV, whereas three were positive to all segments of both viruses, which indicates a possible coinfection (Table 1). These seven samples were from the Southern (Nyanza, Ruhango, and Kamonyi districts) or Northern provinces (Gakenke and Gicumbi districts) (Table 1, Supplemental Figure S2). All cases of BUNV and/or BATV suggested infection were in cattle that had suffered abortions.

Ten RVFV RNA-positive samples had evidence of orthobunyavirus coinfection based on RT-PCR. However, none of them were decisively positive to either BUNV, BATV, or NRIV (Table 1). Overall, two samples amplified the $S$ segment of BUNV, four the M segment, and two the $L$ segment. Three samples in total amplified the BATV $S$ segment and four samples amplified the $M$ segment. There was no amplification of the BATV L segment. Four samples amplified the NRIV S segment, and interestingly none of these samples amplified the BUNV S segment, despite our primers resulting in good cross-amplification. Four samples also amplified the NRIV M segment, and two of those samples also amplified the BATV M segments, whereas the other two did not.

Confirmation of BUNV circulation and detection of orthobunyavirus gene segments in cattle via sequencing. All five of the BUNV-positive samples via RT-PCR were also positive via sequencing (Table 1, Supplemental Table S4). Of those that were suggested to be coinfected with BUNV and BATV, all three had at least one segment confirmed by sequencing. In three instances, the $M$ segment was amplified by the NRIV RT-PCR primers and subsequently sequenced using those primers. However, BLAST indicated identity with the BATV M segment. In all cases (106, 109, and 132), neither the RT-PCR nor sequencing suggested some combination of the BUNV $\mathrm{B}_{S} B \mathrm{VV}_{\mathrm{M}} B U N V_{L}$ to prioritize the suggestion of NRIV over BATV. Only three samples had no successful sequencing of amplicon. Accession numbers for sequences are given in Supplemental Table S4. 
TABLE 1

Summary of results from RT-PCR and sequencing of amplicons

\begin{tabular}{|c|c|c|c|c|c|}
\hline Sample ID & Species & District & RT-PCR-suggested positivity & BUNV sequencing positivity & BATV sequencing positivity \\
\hline 84 & Cow & Gakenke & BUNV+ & + & - \\
\hline 120 & Cow & Gicumbi & BUNV+ & + & - \\
\hline 127 & Cow & Gicumbi & BUNV+ and BATV+ & + & $\mathrm{S}$ \\
\hline 128 & Cow & Ruhango & BUNV+ and BATV+ & + & $\mathrm{S}$ and $\mathrm{M}$ \\
\hline 129 & Cow & Ruhango & BUNV+ and BATV+ & + & $\mathrm{S}$ and $\mathrm{M}$ \\
\hline $132(\mathrm{R}+)$ & Cow & Ruhango & BUNV M and NRIV M & M & $M^{\star}$ \\
\hline $167(\mathrm{R}+)$ & Cow & Ngoma & BUNV S and BATV S & $\mathrm{S}$ & - \\
\hline $108(\mathrm{R}+)$ & Cow & Rwamagana & $\begin{array}{l}\text { BUNV (M and L), BATV S, and NRIV } \\
(\mathrm{S} \text { and } \mathrm{M})\end{array}$ & - & - \\
\hline $198(R+)$ & Cow & Kayonza & BATV (S and M) & - & $\mathrm{S}$ \\
\hline $144(\mathrm{R}+)$ & Cow & Kamonyi & BUNV M, BATV S, and NRIV (S and M) & - & $\mathrm{M}$ \\
\hline 143 & Cow & Kamonyi & BATV+ & - & $\mathrm{S}$ and $\mathrm{M}$ \\
\hline $102(\mathrm{R}+)$ & Goat & Gatsibo & BATV $M$ and NRIV S & - & - \\
\hline $106(\mathrm{R}+)$ & Cow & Rwamagana & BUNV $M$ and NRIV $M$ & M & $M^{*}$ \\
\hline $160(\mathrm{R}+)$ & Cow & Ngoma & BUNV S & - & - \\
\hline $195(\mathrm{R}+)$ & Cow & Ngoma & BATV $S$ and NRIV S & - & - \\
\hline $109(\mathrm{R}+)$ & Cow & Rwamagana & BUNV M, BATV S, and NRIV M & - & S† and $\mathrm{M}^{*}$ \\
\hline 61 & Cow & Nyanza & BUNV S & - & - \\
\hline
\end{tabular}

\section{DISCUSSION}

In this study, we identified RVFV as the causative agent of all cases of hemorrhagic fever among cows and one goat in our sample of these species. Furthermore, RVFV accounted for all clinical disease (hemorrhagic and abortion) in approximately $30 \%$ of sampled cases during the largest RVFV outbreak ever documented in Rwanda. The outbreak highly affected the Eastern Province of Rwanda, which was not surprising as it has been shown to be the most suitable region for mosquito life cycles, as this region is characterized by multiple lakes, rice plantations, low altitude $(<2,300 \mathrm{~m})$, low precipitation, and banana plantations in close proximity to households. ${ }^{60} \mathrm{In}$ deed, a mosquito survey conducted in 2011 showed that this region had the highest density of four of the most One Health relevant mosquito species (in the order of highest density to lowest): Culex spp., Aedes spp., Coquillettidia spp., and Anopheles spp. Culex and Aedes are presumed the primary and secondary vectors of RVFV, and Aedes aegypti and Anopheles gambiae have been shown to be competent vectors for these orthobunyaviruses. ${ }^{22,61,62}$ All districts of the Eastern provinces were affected except Bugesera and Nyagatare districts, where systematic vaccination campaigns had been implemented less than 1 year before the outbreak. This and indication by cattle owners in our study that none of the sampled animals had been vaccinated underscores the utility of high-coverage vaccination programs to preserve the herd health of ruminants to RVFV.

However, for the first time in Rwanda, sequencing of these samples confirms the presence of BUNV and suggests the presence of BATV and/or NRIV, or perhaps uncharacterized derivatives of these orthobunyaviruses. We showed that these orthobunyaviruses, in a small number of cases, were associated with abortions in a small number of ruminants, similar to RVFV, and therefore contributed to the outbreak of the RVFlike illnesses in Rwanda. Furthermore, these observations support our speculation that these pathogens may be causing illness among cattle in neighboring countries. Batai virus has mainly been detected in Europe and Asia, and primarily in avian species, and this is the second molecular confirmation of BATV in Africa since its original identification in Uganda in 1966. ${ }^{45,46,48}$ This could point to a role for migrating birds in the spread of BATV given the African-Eurasian flyway, and there could be opportunity for its range to be broader than what is currently understood. Figure 1 shows the geographic distribution of RT-PCR RVFV+ cases, orthobunyavirus + cases, and RVFV+/Ortho+ cases.

Sequencing was, at times, confounded by volume sample, which could account for the discrepancy in the RT-PCR and sequencing results. In several cases, segments were detected and/or sequenced, but the present study was unable to definitively identify these other orthobunyaviruses, again because of resource limitation. However, our data certainly suggest an important future direction to determine whether BUNV, BATV, and/or NRIV co-circulate and can coinfect among one another and with RVFV.

The provenance of NRIV is unknown, but assumed to have occurred because of a coinfection with BUNV and BATV, largely assumed to have happened in the vector. ${ }^{47}$ However, our study suggested that this may occur in cattle, indicating mammals should not be overlooked as vessels of potential reassortant events. In neighboring countries, other orthobunyaviruses related to BUNV circulate, and this raises the question of whether heretofore unidentified reassortants could be occurring in the region. ${ }^{63,64}$

There is a general dearth of knowledge regarding the ecology of arbovirus transmission in Rwanda. Environmental suitability studies on potential vectors and the role of environmental parameters should be conducted to understand transmission dynamics and offer control solutions, including further characterization of these orthobunyaviruses. The scope of this study was the detection of viral RNA among acutely ill animals during an outbreak of RVF-like illness. However, we speculate that seroprevalence will be higher in 


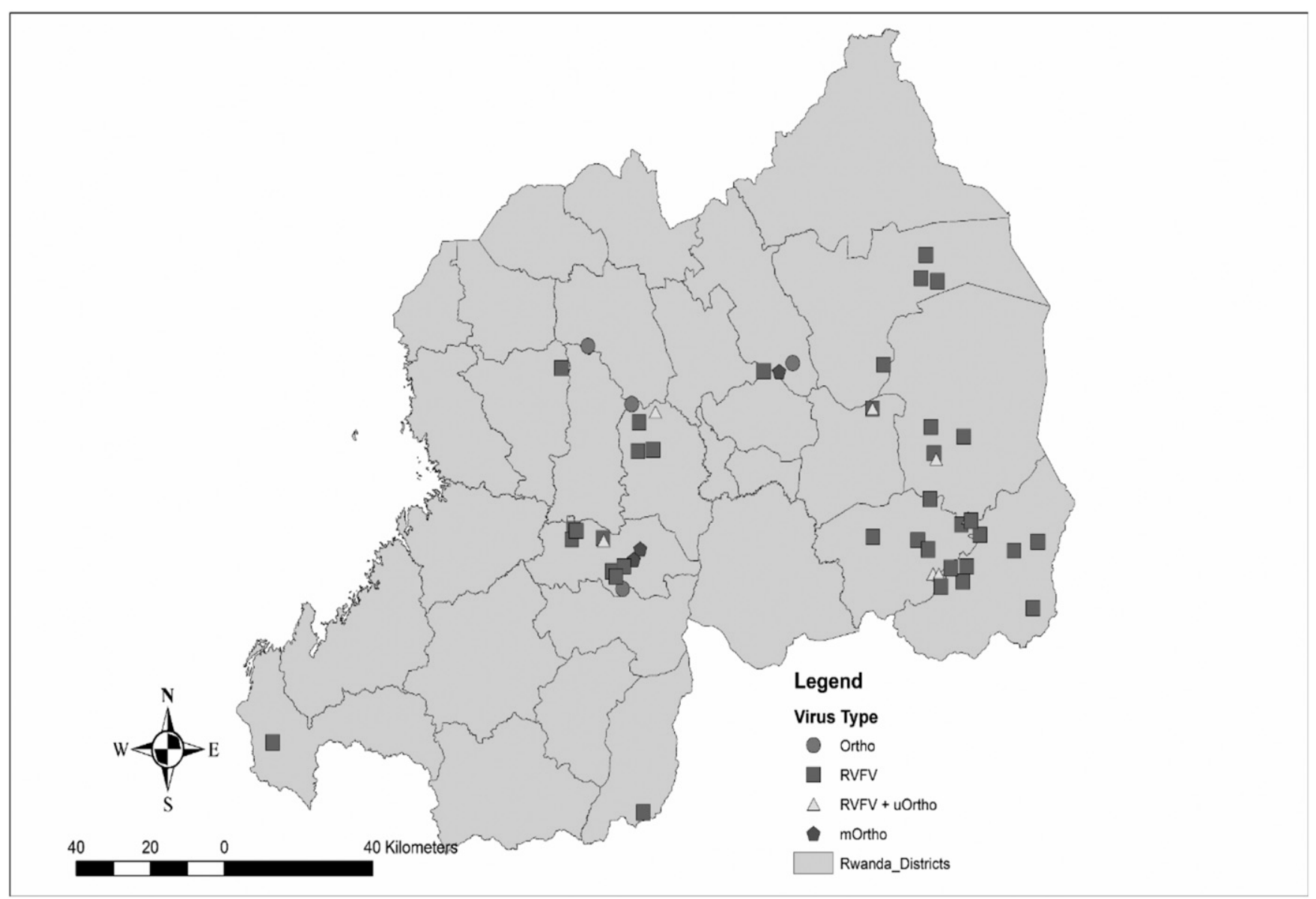

FIGURE 1. Geographic distribution of RVF+ and suggested orthobunyavirus+ cases: Ortho: Bunyamwera virus (BUNV+) or Batai virus (BATV+) cases, Rift Valley fever virus: RVFV+ cases, RVFV+/uOrtho+: potential coinfection between RVFV and orthobunyaviruses; mOrtho: BUNV+/BATV+ coinfection cases. Suggested positivity is via RT-PCR results.

the general cattle population and perhaps in the human population. Importantly, although RVFV was assumed to be the causative agent of disease in this unprecedented outbreak, there was a high proportion of samples negative for all viruses tested here. The etiology of these cases could be due to any number of pathogens that share clinical manifestation, namely, brucellosis and anaplasmosis. These are important issues warranting further research in the region.

Overall, we have demonstrated that RVFV was responsible for $30 \%$ of tested cases with RVF-like illness. We also showed that BUNV and possibly BATV co-circulate with RVFV and were capable of producing acute illness in ruminants. Furthermore, our data suggested that coinfections of orthobunyaviruses and/or RVFV occur and that there may be other orthobunyaviruses circulating in the region that are similarly understudied. Further work is needed to describe the biodiversity of arboviruses in Rwanda, the ecology of such viruses (including vectors, thermal limits of transmission, reservoirs, etc.), and the possibility of causing human disease.

Received August 12, 2019. Accepted for publication March 5, 2020.

Published online April 20, 2020.

Note: Supplemental tables and figures appear at www.ajtmh.org.

Acknowledgments: We thank the Rwanda Agriculture Board for their collaboration and expertise. We also thank Jean Claude Tumushime,
Evodie Uwimbabazi, Elisee Ndizeye, Grace Mukasine, Jean Bosco Noheri, Christopher Mores, Jean de Dieu Ayabagabo, and Ryan Avery for their assistance.

Financial support: This research is based on a work supported by the 1) United States Agency for International Development, as part of the Feed the Future initiative, under the CGIAR Fund, award number BFSG-11-00002, and the predecessor fund the Food Security and Crisis Mitigation II grant, award number EEM-G-00-04-00013; and 2) USDA National Institute of Food and Agriculture, project \#LAV3748, accession \#1015690.

Disclaimer: The contents are solely the responsibility of the authors and do not necessarily represent the official views of the USDA or NIFA.

Authors' addresses: Marie Fausta Dutuze, School of Veterinary Medicine, College of Agriculture and Animal Sciences and Veterinary Medicine, University of Rwanda, Kigali, Rwanda, E-mail: dkmfausta6@ yahoo.fr. Angelique Ingabire, Laboratory technician, Virology laboratory, Rubirizi, Veterinary and Laboratory Services Unit, Animal Research Resources and Transfer Technology Department, Rwanda Agriculture Board, Kigali, Rwanda, E-mail: ingange@yahoo.fr. Isidore Gafarasi, Director of Veterinary and Laboratory Services Unit, Animal Research Resources and Transfer Technology Department, Rwanda Agriculture Board, Kigali, Rwanda, E-mails: gafarasi.isidore@rab.gov.rw and igafarasi@gmail.com. Solange Uwituze, Deputy Director General of Animal Research Resources and Transfer Technology Department, Rwanda Agriculture Board, Kigali, Rwanda, Email: solange.uwituze@ rab.gov.rw. Manassé Nzayirambaho, School of Public Health, College of Medicine and Health Sciences, University of Rwanda, Kigali, Rwanda, E-mail: mnzayira@nursph.org. Rebecca C. Christofferson, School of Veterinary Medicine, Louisiana State University, Baton Rouge, LA, E-mail: rcarri1@|su.edu. 
This is an open-access article distributed under the terms of the Creative Commons Attribution (CC-BY) License, which permits unrestricted use, distribution, and reproduction in any medium, provided the original author and source are credited.

\section{REFERENCES}

1. Clark MHA, Warimwe GM, Di Nardo A, Lyons NA, Gubbins S, 2018. Systematic literature review of Rift Valley fever virus seroprevalence in livestock, wildlife and humans in Africa from 1968 to 2016. PLoS Negl Trop Dis 12: e0006627.

2. Elliott RM, 2013. The Bunyaviridae. New York, NY: Springer Science \& Business Media.

3. Dutuze MF, Nzayirambaho M, Mores CN, Christofferson RC, 2018. A review of Bunyamwera, Batai, and Ngari viruses: understudied orthobunyaviruses with potential one health implications. Front Vet Sci 5: 69.

4. Briese T, Calisher CH, Higgs S, 2013. Viruses of the family Bunyaviridae: are all available isolates reassortants? Virology 446: 207-216.

5. Stordy RJ, 1913. Annual Report Department of Agriculture, British East Africa: 1912-1913 HMSO, ed. London.

6. Daubney R, Hudson JR, Garnham PC, 1931. Enzootic hepatitis or rift valley fever. An undescribed virus disease of sheep cattle and man from East Africa. J Pathol Bacteriol 34: 545-579.

7. Baba M, Masiga DK, Sang R, Villinger J,2016. Has Rift Valley fever virus evolved with increasing severity in human populations in East Africa? Emerg Microbes Infect 5: e58.

8. Ikegami T, Makino S, 2011. The pathogenesis of Rift Valley fever. Viruses 3: 493-519.

9. Bird BH, McElroy AK, 2016. Rift Valley fever virus: unanswered questions. Antiviral Res 132: 274-280.

10. Easterday BC, 1965. Rift Valley fever. Adv Vet Sci 10: 65-127.

11. Findlay GM, Daubney R, 1931. The virus of rift valley fever or enzootic hepatitis. Lancet 218: 1350-1351.

12. Laughlin LW, Girgis NI, Meegan JM, Strausbaugh LJ, Yassin MW, Watten RH, 1978. Clinical studies on Rift Valley fever. Part 2: ophthalmologic and central nervous system complications. J Egypt Public Health Assoc 53: 183-184.

13. Strausbaugh LJ, Laughlin LW, Meegan JM, Watten RH, 1978. Clinical studies on Rift Valley fever, Part I: acute febrile and hemorrhagic-like diseases. J Egypt Public Health Assoc 53: 181-182.

14. van Velden DJ, Meyer JD, Olivier J, Gear JH, McIntosh B, 1977. Rift Valley fever affecting humans in South Africa: a clinicopathological study. S Afr Med J 51: 867-871.

15. Siam AL, Meegan JM, Gharbawi KF, 1980. Rift Valley fever ocular manifestations: observations during the 1977 epidemic in Egypt. Br J Ophthalmol 64: 366-374.

16. Salib M, Sobhy MI, 1978. Epidemic maculopathy. Bull Ophthalmol Soc Egypt 71: 103-106.

17. Deutman AF, Klomp HJ, 1981. Rift Valley fever retinitis. Am J Ophthalmol 92: 38-42.

18. Freed I, 1951. Rift Valley fever in man, complicated by retinal changes and loss of vision. S Afr Med J 25: 930-932.

19. Elliott RM, 1996. The Bunyaviridae. New York, NY: Plenum Press.

20. Soldan SS, González-Scarano F, 2014. The bunyaviridae. Handb Clin Neurol 123: 449-463.

21. Pepin M, Bouloy M, Bird BH, KempA, Paweska J, 2010. Rift Valley fever virus(Bunyaviridae: Phlebovirus): an update on pathogenesis, molecular epidemiology, vectors, diagnostics and prevention. Vet Res 41: 61.

22. Daubney R, Hudson JR, 1932. Rift Valley fever. Lancet 219: 611-612.

23. Davies FG, Highton RB, 1980. Possible vectors of Rift Valley fever in Kenya. Trans R Soc Trop Med Hyg 74: 815-816.

24. Fontenille D, Traore-Lamizana M, Diallo M, Thonnon J, Digoutte JP, Zeller HG, 1998. New vectors of Rift Valley fever in West Africa. Emerg Infect Dis 4: 289-293.

25. Labuda M, Nuttall PA, 2004. Tick-borne viruses. Parasitology 129 (Suppl 1): S221-S245.

26. Lee VH, 1979. Isolation of viruses from field populations of culicoides (Diptera: ceratopogonidae) in Nigeria. J Med Entomol 16: 76-79.
27. Linthicum KJ, Davies FG, Kairo A, Bailey CL, 1985. Rift Valley fever virus (family Bunyaviridae, genus Phlebovirus). Isolations from Diptera collected during an inter-epizootic period in Kenya. J Hyg (Lond) 95: 197-209.

28. Linthicum KJ, Kaburia HF, Davies FG, Lindqvist KJ, 1985. A blood meal analysis of engorged mosquitoes found in Rift Valley fever epizootics area in Kenya. J Am Mosq Control Assoc 1: 93-95.

29. Samy AM, Peterson AT, Hall M, 2017. Phylogeography of Rift Valley fever virus in Africa and the Arabian Peninsula. PLOS Negl Trop Dis 11: e0005226.

30. Archer BN, Weyer J, Paweska J, Nkosi D, Leman P, Tint KS, Blumberg L, 2011. Outbreak of Rift Valley fever affecting veterinarians and farmers in South Africa, 2008. S Afr Med J 101: 263-266.

31. Budasha NH, Gonzalez JP, Sebhatu TT, Arnold E, 2018. Rift Valley fever seroprevalence and abortion frequency among livestock of Kisoro district, South Western Uganda (2016): a prerequisite for zoonotic infection. BMC Vet Res 14: 271.

32. Georges TM, Justin M, Victor M, Marie KJ, Mark R, Leopold MMK, 2018. Seroprevalence and virus activity of Rift Valley fever in cattle in eastern region of democratic republic of the Congo. $J$ Vet Med 2018: 4956378

33. Woods CW et al., 2002. An outbreak of Rift Valley fever in northeastern Kenya, 1997-98. Emerg Infect Dis 8: 138-144.

34. Balkhy HH, Memish ZA, 2003. Rift Valley fever: an uninvited zoonosis in the Arabian peninsula. Int $J$ Antimicrob Agents 21: 153-157.

35. Linthicum KJ, Anyamba A, Tucker CJ, Kelley PW, Myers MF, Peters CJ, 1999. Climate and satellite indicators to forecast Rift Valley fever epidemics in Kenya. Science 285: 397-400.

36. Anyangu AS et al., 2010. Risk factors for severe Rift Valley fever infection in Kenya, 2007. Am J Trop Med Hyg 83: 14-21.

37. World Health Organization, 2007. Diseases Outbreak News. Emergence Prepardness and Response. Accessed March 15, 2019.

38. OIE, 2018. Rift Valley fever, Rwanda Notification Accessed May 16, 2019.

39. OIE, WAHIS Interface, Weekly disease report Accessed May 16, 2019.

40. RAB, 2013. Annual Report 2013. Rwanda Agriculture Board.

41. Umuhoza T, Berkvens D, Gafarasi I, Rukelibuga J, Mushonga B, Biryomumaisho S, 2017. Seroprevalence of Rift Valley fever in cattle along the Akagera-Nyabarongo rivers, Rwanda. J S Afr Vet Assoc 88: e1-e5.

42. Kokernot RH, Smithburn KC, De Meillon B, Paterson HE, 1958. Isolation of Bunyamwera virus from a naturally infected human being and further isolations from Aedes (Banksinella) circumluteolus theo. Am J Trop Med Hyg 7: 579-584.

43. Odhiambo C, Venter M, Limbaso K, Swanepoel R, Sang R, 2014. Genome sequence analysis of in vitro and in vivo phenotypes of Bunyamwera and Ngari virus isolates from northern Kenya. PLoS One 9: e105446.

44. Wertheim HF, Horby P, Woodall JP, eds. 2012. Atlas of Human Infectious Diseases. Hoboken, NJ: Wiley-Blackwell.

45. Singh KR, Pavri KM, 1966. Isolation of Chittoor virus from mosquitoes and demonstration of serological conversions in sera of domestic animals at Manjri, Poona, India. Indian J Med Res 54: 220-224.

46. Nashed NW, Olson JG, el-Tigani A, 1993. Isolation of Batai virus (Bunyaviridae:Bunyavirus) from the blood of suspected malaria patients in Sudan. Am J Trop Med Hyg 48: 676-681.

47. Gerrard SR, Li L, Barrett AD, Nichol ST, 2004. Ngari virus is a Bunyamwera virus reassortant that can be associated with large outbreaks of hemorrhagic fever in Africa. $J$ Virol 78: 8922-8926.

48. Briese T, Bird B, Kapoor V, Nichol ST, Lipkin WI, 2006. Batai and Ngari viruses: $M$ segment reassortment and association with severe febrile disease outbreaks in East Africa. $J$ Virol 80: 5627-5630.

49. Ashford RW, 2001. Encyclopedia of Arthropod-Transmitted Infections of Man and Domesticated Animals. Wallingford, United Kingdom: CABI.

50. Tauro LB, Rivarola ME, Lucca E, Marino B, Mazzini R, Cardoso JF, Barrandeguy ME, Teixeira Nunes MR, Contigiani MS, 2015. First isolation of Bunyamwera virus (Bunyaviridae family) from horses with neurological disease and an abortion in Argentina. Vet J 206: 111-114. 
51. Rodrigues Hoffmann A, Dorniak P, Filant J, Dunlap KA, Bazer FW, de la Concha-Bermejillo A, Welsh CJ, Varner P, Edwards JF, 2013. Ovine fetal immune response to Cache Valley virus infection. J Virol 87: 5586-5592.

52. Medlock JM, Snow KR, Leach S, 2007. Possible ecology and epidemiology of medically important mosquito-borne arboviruses in Great Britain. Epidemiol Infect 135: 466-482.

53. Yanase $T$, Kato $T$, Yamakawa $M$, Takayoshi $K$, Nakamura $K$, Kokuba T, Tsuda T, 2006. Genetic characterization of Batai virus indicates a genomic reassortment between orthobunyaviruses in nature. Arch Virol 151: 2253-2260.

54. Bowen MD et al., 2001. A reassortant bunyavirus isolated from acute hemorrhagic fever cases in Kenya and Somalia. Virology 291: 185-190.

55. Jackel S, Eiden M, El Mamy $B O$, Isselmou K, Vina-Rodriguez A, Doumbia B, Groschup MH, 2013. Molecular and serological studies on the Rift Valley fever outbreak in Mauritania in 2010. Transbound Emerg Dis 60 (Supp/ 2): 31-39.

56. Blitvich BJ et al., 2018. Bunyavirus taxonomy: limitations and misconceptions associated with the current ICTV criteria used for species demarcation. Am J Trop Med Hyg 99: 11-16.
57. Postler TS et al., 2017. Possibility and challenges of conversion of current virus species names to linnaean binomials. Syst Biol 66: 463-473.

58. Christofferson RC, Roy AF, Mores CN, 2010. Factors associated with mosquito pool positivity and the characterization of the West Nile viruses found within Louisiana during 2007. Virol J 7: 139.

59. LaBeaud AD, Sutherland LJ, Muiruri S, Muchiri EM, Gray LR, Zimmerman PA, Hise AG, King CH, 2011. Arbovirus prevalence in mosquitoes, Kenya. Emerg Infect Dis 17: 233-241.

60. Demanou M, 2011. Risk Assessment of Yellow Fever Virus Circulation in Rwanda. Rwanda Ministry of Health.

61. Hartman A, 2017. Rift Valley fever. Clin Lab Med 37: 285-301.

62. Odhiambo C, Venter M, Chepkorir E, Mbaika S, Lutomiah J, Swanepoel R, Sang R, 2014. Vector competence of selected mosquito species in Kenya for Ngari and Bunyamwera viruses. J Med Entomol 51: 1248-1253.

63. CDC. Arbovirus Catalog. Accessed May 17, 2019.

64. Yandoko EN, Gribaldo S, Finance C, Le Faou A, Rihn BH, 2007. Molecular characterization of African orthobunyaviruses. J Gen Virol 88: 1761-1766. 